\title{
Therapy for hyperthermia-induced seizures in Scn1a mutant rats
}

Keiichiro Hayashi ${ }^{1}$, Satoshi Ueshima ${ }^{2}$, Mamoru Ouchida ${ }^{3}$, Tomoji Mashimo ${ }^{4}$, Teiichi

Nishiki ${ }^{1}$, Toshiaki Sendo ${ }^{2}$, Tadao Serikawa ${ }^{4}$, Hideki Matsui ${ }^{1}$ and Iori Ohmori ${ }^{1} *$

${ }^{1}$ Department of Physiology, Graduate School of Medicine, Dentistry, and

Pharmaceutical Sciences, Okayama University, Shikatacho 2-chome 5-1, Kita-ku,

Okayama 700-8558, Japan

${ }^{2}$ Department of Pharmacy, Okayama University Hospital, Shikatacho 2-chome 5-1,

Kita-ku, Okayama 700-8558, Japan

${ }^{3}$ Department of Molecular Genetics, Graduate School of Medicine, Dentistry, and

Pharmaceutical Sciences, Okayama University, Shikatacho 2-chome 5-1, Kita-ku,

Okayama 700-8558, Japan

${ }^{4}$ Institute of Laboratory Animals, Graduate School of Medicine, Kyoto University,

Yoshidakonoe-cho, Sakyo-ku, Kyoto 606-8501, Japan

*Address correspondence to: 
Iori Ohmori, Department of Physiology, Graduate School of Medicine, Dentistry, and Pharmaceutical Sciences, Okayama University, 5-1 Shikata-cho, 2-chome, Okayama 700-8558, Japan

Tel: +81-86-235-7109 Fax: +81-86-235-7111

E-mail: iori@md.okayama-u.ac.jp

Running title: Therapy of Scnla mutant rats

Key words: Scnla gene, Hyperthermia-induced seizure-susceptible rats, Febrile seizure,

Generalized epilepsy with febrile seizures plus, severe myoclonic epilepsy of infancy, predictive validation

Number of text pages: 27 pages

Number of words: 3411 words

Number and proposed size of figures: 5 figures

Number and proposed size of tables: 1 


\section{Summary}

Purpose: Mutations in the $S C N 1 A$ gene, which encodes the $\alpha 1$ subunit of voltage-gated sodium channels, cause generalized epilepsy with febrile seizures plus (GEFS+) and severe myoclonic epilepsy of infancy (SMEI). N1417H-Scnla mutant rats are considered to be an animal model of human FS+ or GEFS+. To assess the pharmacological validity of this model, we compared the efficacies of 8 different antiepileptic drugs (AEDs) for the treatment of hyperthermia-induced seizures using N1417H-Scnla mutant rats. Methods: AEDs used in this study included valproate, carbamazepine (CBZ), phenobarbital, gabapentin, acetazolamide, diazepam (DZP), topiramate, and potassium bromide $(\mathrm{KBr})$. The effects of these AEDs were evaluated using the hot water model, which is a model of experimental FS. Five-week-old rats were pretreated with each AED and immersed in water at $45^{\circ} \mathrm{C}$ to induce hyperthermia-induced seizures. The seizure manifestations and video-electroencephalographic recordings were evaluated. Furthermore, the effects of each AED on motor coordination and balance were assessed using the balance-beam test. Key Findings: $\mathrm{KBr}$ significantly reduced seizure durations, and its anticonvulsant effects were comparable to those of DZP. On the other hand, CBZ decreased the seizure threshold. In addition, DZP and not $\mathrm{KBr}$ showed significant impairment in motor 
coordination and balance. Significance: DZP and $\mathrm{KBr}$ showed potent inhibitory effects against hyperthermia-induced seizures in the Scnla mutant rats, whereas CBZ exhibited adverse effects. These responses to hyperthermia-induced seizures were similar to those in patients with GEFS+ and SMEI. N1417H-Scn1a mutant rats may therefore be useful to test the efficacy of new AEDs against FS in GEFS+ and SMEI patients.

Key words: Febrile seizure, animal models, Scnla gene, Generalized epilepsy with febrile seizures plus, severe myoclonic epilepsy of infancy 


\section{Introduction}

Febrile seizures (FS) are the most common convulsive disorder affecting $2-5 \%$ of children between the ages of 6 months and 6 years (Verity et al., 1985; Hauser et al., 1994; Offringa et al., 2001). Although most FS are benign, known as simple FS, and do not require treatment, $2-7 \%$ of patients with FS subsequently develop epilepsy (Baulac et al., 2004). Generalized epilepsy with febrile seizures plus (GEFS+) is a familial epileptic syndrome characterized by FS persisting beyond 6 years and subsequent development of various types of epilepsy, including generalized tonic-clonic, myoclonic, and absence seizures (Scheffer and Berkovic, 1997). In severe myoclonic epilepsy of infancy (SMEI; also known as Dravet syndrome), repetitive FS begin in the first year of life, and life-threatening status epilepticus is often provoked by fever. Therefore, appropriate treatment of FS is important for patients with GEFS+ and SMEI.

Heterozygous mutations in $S C N 1 A$, a gene encoding the $\alpha 1$ subunit in voltage-gated sodium channels $\left(\mathrm{Na}_{\mathrm{V}} 1.1\right)$, are responsible for GEFS+ and SMEI. Mutations in SCN1A account for $80 \%$ of SMEI cases and $10 \%$ of GEFS + cases (Claes et al., 2001; Ohmori et al., 2002; Hattori et al., 2008). Developments in genetic engineering have enabled the generation of various genetically modified animals, and many researchers can now investigate pathology and new disease treatments using these animals. 
Recently, Mashimo et al. generated Scnla mutant rats (F344/NSlc-Scnla $a^{\text {Kyo811 }}$ ) with the missense mutation, N1417H, using ENU mutagenesis (2008, 2010). These N1417H-Scnla mutant rats are considered an animal model of human FS+ or GEFS+. Generally, animal models of human diseases are required to fulfill three criteria, namely face validity, construct validity, and predictive validity (Chadman et al., 2009). Face validity incorporates a conceptual analogy to the symptoms of the human disease. Homozygous N1417H-Scnla mutant rats exhibited susceptibility to hyperthermia-induced seizures, and their seizures persisted over the age of 5 weeks, whereas WT rats were unaffected. (Mashimo, et al., 2010). Therefore, this model rat showed similar febrile seizures to those seen in patients with GEFS+ and SMEI. Second, construct validity incorporates a conceptual analogy to the cause of the human disease. These rats have an $\mathrm{N} 1417 \mathrm{H}$ missense mutation in the causative SCN1A gene of GEFS+ and SMEI. N1417H was not detected in human patients, but the electrophysiological properties of $\mathrm{N} 1417 \mathrm{H}$ share a common molecular basis of most of SMEI, and some GEFS+ patients. Namely, the recombinant N1417H-human SCN1A mutation was revealed to have a loss-of-function effect on $\mathrm{Na}_{\mathrm{v}} 1.1$, and the hippocampal neurons of these rats demonstrated impaired biophysical properties of inhibitory GABAergic neurons (Mashimo et al., 2010). We have confirmed that N1417H-Scnla mutant rats 
fulfilled these two criteria in our previous study. Here, we addressed the third criterion, predictive validity. It incorporates the specificity of responses to treatments that are effective in the human disease. We herein evaluated the efficacy of antiepileptic drugs (AEDs) on hyperthermia -induced seizures in the model rats. Potassium bromide (KBr), a traditionally prescribed AED, was found to be as effective as DZP, while CBZ showed adverse effects. These drug-mediated responses to hyperthermia-induced seizures in the new model rats were similar to those in patients with GEFS+ or SMEI.

\section{Materials and Methods}

\section{Animals}

Male homozygous N1417H-Scnla mutant rats (F344/NSlc-Scn1a ${ }^{\text {Kyo811 }}$ ) (National Bio Resource Project for the Rat in Japan, Kyoto University, Kyoto, Japan) were used to assess the effects of AEDs against hyperthermia-induced seizures. The susceptibility of wild-type rats to hyperthermia decreases with age, and therefore, these 5-week-old rats showed no indications of hyperthermia-induced seizures, whereas the homozygous N1417H-Scnla mutant rats demonstrated generalized tonic-clonic seizures induced by hyperthermia until at least 10 weeks of age (Mashimo et al., 2010). The rats were maintained under standard laboratory conditions with a 12-h light/dark cycle and food 
and water ad libitum. All experiments were performed in accordance with protocols approved by the Institutional Animal Care and Use Committee of Okayama University.

\section{Induction of hyperthermia-induced seizures}

Experimental FS have been extensively studied in a well-established model, in which FS are evoked by exposing the rat pups (postnatalday 8-15) to heated air (Holtzman et al., 1981; Schuchmann et al., 2006), hot water jet on the heads (Ullal et al., 1996), or hot water bathing (Klauenberg and Sparber, 1984). We used hot water bathing from the view point of animal welfare, namely heated air requires longer exposure of the rats to hyperthermic environment and induces more severe seizures compared with hot water bathing (Supplementary Fig. 1). Induction of hyperthermia-induced seizures was performed as described previously, with slight modifications (Mashimo et al., 2010). Hyperthermia was induced by placing the rats in a $19.0 \times 24.7 \times 15.5 \mathrm{~cm}$ water bath (Thermo minder SD mini, Taitec, Japan) filled with water at $45^{\circ} \mathrm{C}$ to a depth of $6 \mathrm{~cm}$ (Fig. 1A). The rats were kept in the water for a maximum of 5 min or until a seizure occurred. We confirmed that immersing the rats in $37^{\circ} \mathrm{C}$ and $40^{\circ} \mathrm{C}$ water for 5 min did not evoke seizures (Supprementary Fig. 2). When a seizure occurred, the rats were immediately removed from the bath and monitored until they recovered. Rectal 
temperature of the rats was measured immediately after seizure onset using a digital thermometer (BDT-100, Bioresearch Center, Japan) connected to rectal probe (Ret-2, Physitemp, USA). Each rat was assigned a score based on the most severe seizure observed. The seizure parameters were scored as follows: (0) no response; (1) head nodding with brief twitching movements (Fig. 1B); (2) repetitive myoclonic jerks with postural tone (Fig. 1C); (3) jumping and/or running fits (Fig. 1D); (4) generalized tonic-clonic seizure with loss of postural tone (Fig. 1E); and (5) death due to continuous convulsions. Seizure parameters were scored by an investigator who was blinded to the treatment received. All procedures were recorded using a video camera.

\section{Treatment with AEDs}

To assess the pharmacological validation of N1417H-Scnla mutant rats, AEDs which have been established to be effective in patients with GEFS+ and SMEI were chosen. AEDs used in the present study included sodium valproate (VPA-Na; Sigma-Aldrich, Japan), phenobarbital sodium (PB-Na; Wako, Japan), diazepam (DZP; Wako, Japan), carbamazepine (CBZ; Sigma-Aldrich, Japan), acetazolamide sodium (AZA-Na; Diamox, Sanwa, Japan), potassium bromide (KBr; Wako, Japan), topiramate (TPM; Toronto Research Chemicals, Canada), and gabapentin (GBP; Toronto Research Chemicals, 
Canada). VPA-Na, PB-Na, AZA-Na, $\mathrm{KBr}$, and GBP were dissolved in saline. CBZ, DZP, and TPM were suspended in $10 \%$ polyethylene glycol 400 with saline. The rats were fasted overnight and orally administered each AED. Experimental conditions were determined based on the results of preliminary studies (Supplementary Fig. 3). As the appropriate range of each AED for the model rats is not known, we referred to the doses used to treat human epilepsy. The therapeutic range of each AED was determined according to previous literatures as follows; VPA, 40-120 $\mu \mathrm{g} / \mathrm{ml}$ (Schmidt, 2009); CBZ, 4-12 $\mu \mathrm{g} / \mathrm{ml}$ (Eadie, 2001); PB, 10-40 $\mu \mathrm{g} / \mathrm{ml}$ (Schmidt, 2009); GBP, 2-20 $\mu \mathrm{g} / \mathrm{ml}$ (McLean, 1999); AZA, 10-20 $\mu \mathrm{g} / \mathrm{ml}$ (Granero et al., 2007); DZP, 0.2-0.6 $\mu \mathrm{g} / \mathrm{ml}$ (Ogutu et al., 2002); and $\mathrm{KBr}, 500-1500 \mu \mathrm{g} / \mathrm{ml}$ (Ryan and Baumann, 1999). In cases where the blood concentration did not reach the therapeutic range, a higher dose was administrated to achieve a concentration higher than the top of the therapeutic range of each AED. Seizures were induced when the blood concentration of each AED elevated to an adequate level. VPA-Na (200 mg/kg) was administered for $30 \mathrm{~min}$; CBZ (200 mg/kg), 120 min; PB-Na (50 mg/kg), 240 min; GBP (100 mg/kg), 90 min; AZA-Na (55 mg/kg), 30 min; DZP (5 mg/kg), 15 min; TPM (80 mg/kg), $90 \mathrm{~min}$; and KBr (1800 mg/kg), 90 min before seizures were induced. Experimental conditions of DZP and TPM administration were determined based on previous studies (Ishihara et al., 2000; 
Borowicz et al., 2003; Sendrowski et al., 2007). The temperature threshold was measured using the rectal temperature of the rats immediately after seizure onset, in addition to the duration of the seizure and the seizure severity score. After seizure termination, blood samples were obtained from the tail vein of the rats, and the blood concentration of each AED was then measured. Measurement of the blood concentrations of each AED was performed as described in Supplemental Methods.

\section{Electroencephalography}

Ictal electroencephalogram (EEG) patterns were also analyzed for four AEDs (AZA, TPM, DZP, and $\mathrm{KBr}$ ) which exhibits remarkable therapeutic effects and CBZ, which may aggravate hyperthermia-induced seizures. At 4 weeks of age, the rats were implanted with electrodes for EEG recordings. Under pentobarbital sodium anesthesia (35 mg/kg, i.p.; Nembutal, Abbott Laboratories, USA), the rats were fixed to a stereotaxic apparatus (SR-5M, Narishige, Japan). Stainless steel screw electrodes $(2.0 \varnothing$ $\times 0.6 \times 1.7 \mathrm{~mm}$; Fukuoka Seimitsu, Japan) were implanted bilaterally into the frontal cortex (AP: $+0.5 \mathrm{~mm}$; ML: $\pm 3.0 \mathrm{~mm}$ from bregma) and occipital cortex (AP: $-7.0 \mathrm{~mm}$; ML: $\pm 3.0 \mathrm{~mm}$ from bregma). In addition, a stainless steel screw implanted into the posterior end of the skull served as a reference electrode. This assembly was fixed to the 
skull with dental cement (UNIFAST II, GC Dental Products, Japan). After a 1-week recovery period, cortical EEGs were recorded through electroencephalography (Neurofax EEG-1200, Nihon Koden, Japan). The duration of the seizure discharges between seizure onset and termination were analyzed.

\section{Balance-beam test}

Each AED has various side effects on the central nervous system, gastrointestinal organs, urinary tracts, and so on, especially following chronic use. In the present study, we only assessed the acute effects on motor coordination and balance because AEDs were administered as a single dose. This test was performed as described previously, with slight modifications (Carter et al., 1999; Perez et al., 2005). The beam was $105 \mathrm{~cm}$ long, $35 \mathrm{~mm}$ wide, and was elevated $100 \mathrm{~cm}$ above the ground. A black box $(20 \times 18 \times$ $30 \mathrm{~cm}$ ) was set at one end of the beam as the goal. A bright light was situated opposite the goal box to encourage the rats to cross the beam (Fig. 5A). The rats were first trained to traverse the beam and were then tested. Crossing time and the number of footfalls were recorded.

\section{Statistical analysis}

Data are presented as mean \pm SEM. Data analyses were performed using non-repeated 
measures ANOVA with Dunnett's post hoc test. Seizure severity scores were analyzed using the Kruskal-Wallis $\mathrm{H}$ test together with the Mann-Whitney U test, followed by the Bonferroni correction post hoc test. Statistical difference was defined as $\mathrm{p}<0.05$.

\section{Results}

Effects of AEDs on hyperthermia-induced seizures

In order to evaluate which AEDs are effective against hyperthermia-induced seizures in Scnla mutant rats, we induced seizures by immersing the rats pretreated with each AED in water at $45^{\circ} \mathrm{C}$. The anticonvulsant effects of AEDs were assessed using 4 parameters: incidence of seizure; temperature threshold, calculated from the rectal temperature of the rats immediately after seizure onset; seizure duration; and seizure severity score. $\mathrm{DZP}$ and $\mathrm{KBr}$, but no other AEDs, reduced the incidence rate of hyperthermia-induced seizures (Fig. 2A). PB, DZP, TPM, and $\mathrm{KBr}$ significantly increased the temperature threshold, whereas CBZ, GBP, and AZA decreased the threshold (Fig. 2B). All AEDs, except CBZ, significantly decreased the seizure duration (Fig. 2C). In particular, AZA, DZP, and $\mathrm{KBr}$ shortened the seizure duration dramatically (Fig. 2C). Although DZP and $\mathrm{KBr}$ tended to reduce the seizure severity scores, significant changes were not observed (Fig. 2D). 
After seizure termination, blood samples were obtained from the tail vein of the rats, and blood concentrations of the AEDs were then measured. Blood concentrations of all AEDs, except those of DZP, increased over the therapeutic range (Table 1). Although the serum level of DZP did not reach the therapeutic range in the $5 \mathrm{mg} / \mathrm{kg}$ DZP-treated group, these rats showed ataxia and lethargy in the hot bath; therefore, the dose of DZP was not increased. We couldn't exclude the possibility that higher doses of some of AEDs may have lead to the different results.

\section{Electroencephalography}

Ictal EEG patterns were examined in 5 AEDs (AZA, TPM, DZP, KBr and CBZ). Representative ictal EEG recordings from the rats are shown in Figs. 3 and 4A. It was observed that seizures began as tonic seizures with high frequency spikes, followed by clonic seizures (Fig. 4A). Hyperthermia-induced seizures in Scnla mutant rats were often provoked as several recurrent seizures with a few seconds interval between the seizures. Before the second tonic-clonic seizure occurs, interictal spikes appear and gradually increase their amplitude. Between the first seizure and the second seizure, high amplitude spikes were associated with myoclonic jerks. We analyzed the duration of the seizure discharges on EEGs between seizure onset and termination (Fig. 4A). 
AZA, DZP, and $\mathrm{KBr}$ significantly reduced the duration of the seizure discharges, whereas CBZ and TPM showed no significant changes (Fig. 4B).

Balance-beam test

Motor coordination and balance were examined using the balance-beam test for some of the AEDs which showed remarkable inhibitory effects on hyperthermia-induced seizures (Fig. 5A, B). Although control (i.e., untreated) rats walked along the beam with ease, motor deficits were observed in the PB- and DZP-treated groups (Fig. 5C, D). On the other hand, AZA and $\mathrm{KBr}$ did not affect motor coordination or balance (Fig. $5 \mathrm{C}$, D).

\section{Discussion}

In total, more than 600 mutations in the $S C N 1 A$ gene have been identified in patients with SMEI and GEFS+. SCN1A is the most representative mutated gene in human fever-related epileptic syndromes. Patients with SMEI suffer from life-threatening status epilepticus, which is often provoked by fever, and patients with GEFS+ have repetitive FS that can persist beyond 6 years. Therefore, induction of appropriate treatments for FS in the early stages of onset is essential for these patients. 
Rodent models harboring the responsible mutant genes are often used to elucidate the molecular pathogenesis and to cultivate novel treatments. Scnla KO mice (Yu et al., 2006; Ogiwara et al., 2007) and R1648H-Scnla mice (Martin et al., 2010) were generated to investigate the $S C N 1 A$ gene. Both types of heterozygous mutant mice exhibited susceptibility to hyperthermia-induced seizures (Oakley et al., 2009; Martin et al., 2010). Homozygous N1417H-Scnla mutant rats in the present study also exhibited susceptibility to hyperthermia-induced seizures.

In the present study, the effects of AEDs on hyperthermia-induced seizures were assessed in homozygous $\mathrm{N} 1417 \mathrm{H}-\mathrm{Scn} 1 \mathrm{a}$ mutant rats. DZP and $\mathrm{KBr}$ showed potent effects on hyperthermia-induced seizures in these rats. DZP and $\mathrm{KBr}$ demonstrated reduction in the incidence of seizures, increase in the temperature threshold, and shortening of the seizure duration. Furthermore, DZP and $\mathrm{KBr}$ also decreased the duration of the seizure discharges on EEG. In the balance-beam test, DZP significantly increased the crossing time and total number of footfalls, whereas $\mathrm{KBr}$ did not demonstrate a significant effect on these parameters. Together with the blood level of each AED, these results suggested that DZP in low doses, but not $\mathrm{KBr}$ in high doses, influences motor coordination and balance. When the pharmacokinetics between DZP and $\mathrm{KBr}$ were compared, DZP was shown to be effective in the short term, whereas $\mathrm{KBr}$ 
was shown to have a long half-life (12 days) in blood. Development of tolerance to DZP in long-term treatment is well known (Haigh and Feely, 1988). Since DZP is the first choice for treatment of status epilepticus because of its potent anticonvulsant effects, prolonged administration of DZP may decrease the effectiveness of stopping seizures in case of status epilepticus. Therefore, $\mathrm{KBr}$ may be recommended for repetitive FS.

PB, VPA and TPM also showed efficacy for preventing hyperthermia-induced seizures. AZA and GBP decreased the seizure threshold but shortened the duration of seizures. However, the molecular mechanisms that induce hyperthermia-induced seizures and terminate seizures remain unknown. The results presented here suggest that the mechanisms that increase the seizure threshold and terminate seizures are different. Although AZA is mainly used for treating absence seizures, its ability to shorten seizures is remarkable. Hyperthermia-induced respiratory alkalosis involves the onset of hyperthermia-induced seizures (Schchmann et al., 2006), and metabolic acidosis terminates seizures and prevents seizure progression (Ziemann et al., 2008). AZA, a carbonic anhydrase inhibitor, is known to cause metabolic acidosis. In fact, AZA-Na $(55 \mathrm{mg} / \mathrm{kg})$ decreased the peripheral venous blood $\mathrm{pH}$ of rats from $7.38 \pm 0.01$ to $7.22 \pm$ 0.01 within $30 \mathrm{~min}$ of oral administration. This acidosis may have been partially responsible for decrease in the seizure duration in the AZA-treated group. These 
findings suggest that AZA is useful for terminating prolonged seizures, but not for inhibiting seizure onset.

Almost all AEDs have a partial effect on hyperthermia-induced seizures. CBZ, on the other hand, significantly reduced the seizure threshold, suggesting that CBZ may aggravate hyperthermia-induced seizures because of its sodium channel blocking effects (Macdonald et al., 2002).

Taken together, $\mathrm{KBr}$ and $\mathrm{DZP}$ are first-line treatments for hyperthermia-induced seizures in Scnla mutant rats; PB, TPM and VPA are second-line treatments. It was observed that AZA suppressed and CBZ aggravated hyperthermia-induced seizures. However, how much of these results in the Scnla mutant rats mimic the results of human epilepsy with SCN1A mutation? In patients with SMEI, of which more than $80 \%$ have a mutation in $S C N 1 A$, benzodiazepines and VPA are effective in preventing seizures (Ceulemans et al., 2004). KBr also improved generalized tonic-clonic seizures, generalized clonic seizures, and complex partial seizures (Oguni et al., 1994). KBr is known to induce several adverse effects such as drowsiness, headache, acneiform rashes, and loss of appetite. The significant toxicity associated with their use and the availability of safer AEDs may lead to a decrease in the use of $\mathrm{KBr}$. The inhibitory effects of TPM as monotherapy were almost equal to those induced by VPA and PB. 
The clinical efficacy of TPM as adjunctive therapy has been reported in SMEI patients (Nieto-Barrera et al., 2000, Coppola et al., 2002). Regarding the adverse effects of CBZ in the model rats, CBZ also aggravated seizures in patients with SMEI and GEFS+ (Guerrini et al., 1998; Horn et al., 1986). These reports in humans are consistent with the results presented here in the Scnla mutant rats. Scnla mutant rats seem to considerably reflect the pathogenesis of human SCN1A mutation-associated epilepsy. Considering the many differences, such as the way of treatment, treatment dose, type of seizure, age, gender, genetic background, and environmental factors, these rats may be useful for screening new AEDs or novel treatments for FS associated with SCN1A mutations in order to predict drugs that might be effective in human patients. 


\section{Acknowledgments}

We are thankful to Prof. Chiaki Kamei for technical support regarding the EEG recordings. We are thankful to the National Bio Resource Project for the Rat in Japan (http://www.anim.med.kyoto-u.ac.jp/NBR/) for providing rat strains (F344/NSlc-Scnl $a^{K y o 811}$ ). This work was supported by a Grant-in-Aid from the Ministry of Education, Culture, Sports, Science, and Technology (No. 21390312 to I.O.).

We confirm that we have read the Journal's position on issues involved in ethical publication and affirm that affirm that this report is consistent with those guidelines

Disclosure of Conflicts of Interest: None of the authors has any conflict of interest to disclose. 


\section{References}

Baulac S, Gourfinkel-An I, Nabbout R, Huberfeld G, Serratosa J, Leguern E, Baulac M (2004) Fever, genes, and epilepsy. Lancet Neurol 3:421-30.

Borowicz KK, Luszczki JJ, Duda AM, Czuczwar SJ (2003) Effect of topiramate on the anticonvulsant activity of conventional antiepileptic drugs in two models of experimental epilepsy. Epilepsia 44:640-6.

Carter RJ, Lione LA, Humby T, Mangiarini L, Mahal A, Bates GP, Dunnett SB, Morton AJ (1999) Characterization of progressive motor deficits in mice transgenic for the human Huntington's disease mutation. J Neurosci 19:3248-57.

Ceulemans B, Boel M, Claes L, Dom L, Willekens H, Thiry P, Lagae L (2004) Severe myoclonic epilepsy in infancy: toward an optimal treatment. J Child Neurol 19:516-21.

Chadman KK, Yang M, Crawley JN (2009) Criteria for validating mouse models of psychiatric diseases. Am J Med Genet B Neuropsychiatr Genet. 5;150B:1-11.

Claes L, Del-Favero J, Ceulemans B, Lagae L, Van Broeckhoven C, De Jonghe P (2001) De novo mutations in the sodium-channel gene SCN1A cause severe myoclonic epilepsy of infancy. Am J Hum Genet 68:1327-32. 
Eadie MJ (2001) Therapeutic drug monitoring-antiepileptic drugs. Br J Clin Pharmacol 52 Suppl 1:11S-20S.

Granero GE, Longhi MR, Becker C, Junginger HE, Kopp S, Midha KK, et al. (2007) Biowaiver monographs for immediate release solid oral dosage forms: Acetazolamide. J Pharm Sci 97:3691-99.

Guerrini R, Dravet C, Genton P, Belmonte A, Kaminska A, Dulac O (1998) Lamotrigine and seizure aggravation in severe myoclonic epilepsy. Epilepsia 39:508-12.

Haigh JR \& Feely M (1988) Tolerance to the anticonvulsant effect of benzodiazepines. Trends Pharmacol Sci 9:361-6.

Hattori J, Ouchida M, Ono J, Miyake S, Maniwa S, Mimaki N, Ohtsuka Y, Ohmori I. (2008) A screening test for the prediction of Dravet syndrome before one year of age. Epilepsia 49:626-33.

Hauser WA (1994) The prevalence and incidence of convulsive disorders in children. Epilepsia 35 Supp1 2:S1-6.

Holtzman D, Obana K, Olson J (1981) Hyperthermia-induced seizures in the rat pup: a model for febrile convulsions in children. Science 213:1034-6.

Horn CS, Ater SB, Hurst DL (1986) Carbamazepine-exacerbated epilepsy in children 
and adolescents. Pediatr Neurol 2:340-5.

Ishihara K, Kushida H, Yuzurihara M, Wakui Y, Yanagisawa T, Kamei H, Ohmori S, Kitada M (2000) Interaction of drugs and Chinese herbs: pharmacokinetic changes of tolbutamide and diazepam caused by extract of Angelica dahurica. $J$ Pharm Pharmacol 52:1023-9.

Klauenberg BJ \& Sparber SB (1984) A kindling-like effect induced by repeated exposure to heated water in rats. Epilepsia 25:292-301.

Laorden ML, Carrillo E, Miralles FS, Puig MM (1990) Effects of diltiazem on hyperthermia induced seizures in the rat pup. Gen Pharmacol 21:313-5.

Macdonald RL (2002), Carbamazepine, Levy RH, Mattson RH, Meldrum BS, Perucca E (eds) Antiepileptic Drugs, Lippincott Williams \& Wilkins, Philadelphis, pp. 227-235.

Martin MS, Dutt K, Papale LA, Dubé CM, Dutton SB, de Haan G, Shankar A, Tufik S, Meisler MH, Baram TZ, Goldin AL, Escayg A. (2010) Altered function of the SCN1A voltage-gated sodium channel leads to gamma-aminobutyric acid-ergic (GABAergic) interneuron abnormalities. J Biol Chem 285:9823-34.

Mashimo T, Yanagihara K, Tokuda S, Voigt B, Takizawa A, Nakajima R, Kato M, Hirabayashi M, Kuramoto T, Serikawa T. (2008) An ENU-induced mutant archive 
for gene targeting in rats. Nat Genet 40:514-5.

Mashimo T, Ohmori I, Ouchida M, Ohno Y, Tsurumi T, Miki T, Wakamori M, Ishihara S, Yoshida T, Takizawa A, Kato M, Hirabayashi M, Sasa M, Mori Y, Serikawa T. (2010) A missense mutation of the gene encoding voltage-dependent sodium channel (Nav1.1) confers susceptibility to febrile seizures in rats. $J$ Neurosci 30:5744-53.

McLean M (1999) Gabapentin in the management of convulsive disorders. Epilepsia 40 Suppl 6:S39-50; discussion S73-4.

Oakley JC, Kalume F, Yu FH, Scheuer T, Catterall WA (2009) Temperature- and age-dependent seizures in a mouse model of severe myoclonic epilepsy in infancy. Proc Natl Acad Sci U S A 106:3994-9.

Offringa M \& Moyer VA (2001) Evidence based paediatrics: Evidence based management of seizures associated with fever. BMJ 323:1111-4.

Ogiwara I, Miyamoto H, Morita N, Atapour N, Mazaki E, Inoue I, Takeuchi T, Itohara S, Yanagawa Y, Obata K, Furuichi T, Hensch TK, Yamakawa K. (2007) Na(v)1.1 localizes to axons of parvalbumin-positive inhibitory interneurons: a circuit basis for epileptic seizures in mice carrying an Scn1a gene mutation. J Neurosci 27:5903-14.

Oguni H, Hayashi K, Oguni M, Mukahira A, Uehara T, Fukuyama Y, Umezu R, Izumi T, Hara M. (1994) Treatment of severe myoclonic epilepsy in infants with bromide 
and its borderline variant. Epilepsia 35:1140-5.

Ogutu BR, Newton CR, Crawley J, Muchohi SN, Otieno GO, Edwards G, et al. (2002) Pharmacokinetics and anticonvulsant effects of diazepam in children with severe falciparum malaria and convulsions. Br J Clin Pharmacol 53:49-57.

Ohmori I, Ouchida M, Ohtsuka Y, Oka E, Shimizu K (2002) Significant correlation of the SCN1A mutations and severe myoclonic epilepsy in infancy. Biochem Biophys Res Commun 295:17-23.

Perez FA \& Palmiter RD. (2005) Parkin-deficient mice are not a robust model of parkinsonism. Proc Natl Acad Sci U S A 102:2174-9.

Ryan M \& Baumann RJ (1999) Use and monitoring of bromides in epilepsy treatment. Pediatr Neurol 21:523-8.

Scheffer IE \& Berkovic SF (1997) Generalized epilepsy with febrile seizures plus. A genetic disorder with heterogeneous clinical phenotypes. Brain 120:479-90.

Schmidt D (2009) Drug treatment of epilepsy: Options and limitations. Epilepsy Behav $15: 56-65$.

Schuchmann S, Schmitz D, Rivera C, Vanhatalo S, Salmen B, Mackie K, Sipilä ST, Voipio J, Kaila K. (2006) Experimental febrile seizures are precipitated by a hyperthermia-induced respiratory alkalosis. Nat Med 12:817-23. 
Sendrowski K, Sobaniec W, Sobaniec-Lotowska ME, Artemowicz B (2007) Topiramate as a neuroprotectant in the experimental model of febrile seizures. Adv Med Sci 52 Suppl 1:161-5.

Ullal GR, Satishchandra P, Shankar SK (1996) Hyperthermic seizures: an animal model for hot-water epilepsy. Seizure 5:221-8.

Verity CM, Butler NR, Golding J (1985). Febrile convulsions in a national cohort followed up from birth. I-Prevalence and recurrence in the first five years of life. $\mathrm{Br}$ Med J (Clin Res Ed) 290:1307-10.

Yu FH, Mantegazza M, Westenbroek RE, Robbins CA, Kalume F, Burton KA, Spain WJ, McKnight GS, Scheuer T, Catterall WA. (2006) Reduced sodium current in GABAergic interneurons in a mouse model of severe myoclonic epilepsy in infancy. Nat Neurosci 9:1142-9.

Ziemann AE, Schnizler MK, Albert GW, Severson MA, Howard MA 3rd, Welsh MJ, Wemmie JA. (2008) Seizure termination by acidosis depends on ASIC1a. Nat Neurosci 11:816-22. 


\section{Figure Legends}

Figure 1. Hyperthermia-induced seizures in Scnla mutant rats. (A) Hyperthermia was induced by placing the rats in a water bath filled with water at $45^{\circ} \mathrm{C}$. (B) Head nodding and brief twitching movements were classified as a score of 1. (C) Repetitive myoclonic jerks of the forelimbs with a postural tone were classified as a score of 2. (D) Jumping and/or running fits were classified as a score of 3. (E) Generalized tonic-clonic seizures with loss of postural tone were classified as a score of 4 .

Figure 2. Comparison of effects of AEDs on hyperthermia-induced seizures in Scnla mutant rats. (A) Suppression rate of seizures (\%). (B) Temperature threshold. Rectal temperature of the rats was measured immediately after seizure onset (C) Seizure duration (D) Seizure severity score. Untreated (Cont., $\mathrm{n}=9$ ), VPA-Na (200 mg/kg, $\mathrm{n}=$ 8), CBZ (200 mg/kg, n = 7), PB-Na (50 mg/kg, $\mathrm{n}=7)$, GBP (100 mg/kg, $\mathrm{n}=7)$, AZA-Na (55 mg/kg, $\mathrm{n}=12)$, DZP (5 mg/kg, $\mathrm{n}=7)$, TPM (80 mg/kg, $\mathrm{n}=8)$, and $\mathrm{KBr}$ $(1800 \mathrm{mg} / \mathrm{kg}, \mathrm{n}=7)$. Data are mean \pm SEM. ${ }^{*} \mathrm{p}<0.05, * * \mathrm{p}<0.01$ compared to controls (untreated).

Figure 3. Representative ictal EEG patterns of a hyperthermia-induced seizure after 
treatment with each AED. The top and bottom traces were from the frontal and occipital cortices, respectively.

Figure 4. A representative ictal EEG of a hyperthermia-induced seizure from Scnla mutant rats. (A) A Seizure began as tonic seizures (the first arrow) with high frequency spikes, followed by clonic seizures. Hyperthermia-induced seizures were often provoked as several recurrent seizures with a few seconds interval between the seizures. Before the second tonic seizure occurs (the second arrow), high amplitude spikes were associated with myoclonic jerks. The asterisk $(*)$ indicates myoclonic jerks. After the termination of seizures, repetitive spikes continued for several seconds with no seizure manifestations (B) The duration of the seizure discharges between seizure onset (the first arrow) and termination (the third arrow) was measured. Untreated (Cont., $\mathrm{n}=8$ ), CBZ (200 mg/kg, n =6), AZA-Na (55 mg/kg, n = 7), TPM (80 mg/kg, n =6), DZP (5 $\mathrm{mg} / \mathrm{kg}, \mathrm{n}=8)$, and $\mathrm{KBr}(1800 \mathrm{mg} / \mathrm{kg}, \mathrm{n}=7)$. Data are mean \pm SEM. ${ }^{*} \mathrm{p}<0.05,{ }^{*} \mathrm{p}<$ 0.01 compared to controls (untreated).

Figure 5. Balance-beam test apparatus for measuring motor coordination and balance. (A) A bright light was placed opposite the black box to encourage the rats to perform 
the task. The time they took to cross the beam was recorded. (B) The number of times the hind limb slipped off the beam was counted. (C) Time to cross the beam after treatment with each AED. (D) Number of footfalls while crossing the beam after treatment with each AED. Untreated (Cont., $\mathrm{n}=14)$, PB-Na $(50 \mathrm{mg} / \mathrm{kg}, \mathrm{n}=15)$, AZA-Na (55 mg/kg, $\mathrm{n}=14)$, DZP (5 mg/kg, $\mathrm{n}=7)$, and $\mathrm{KBr}(1800 \mathrm{mg} / \mathrm{kg}, \mathrm{n}=10)$. Data are mean \pm SEM. ${ }^{*} \mathrm{p}<0.05, * * \mathrm{p}<0.01$ compared to controls (untreated). 
Table 1. Blood concentrations of antiepileptic drugs immediately after hyperthermia-induced seizures in Scnla mutant rats.

\begin{tabular}{lccccl}
\hline & $\mathrm{n}$ & $\begin{array}{c}\text { Dose } \\
(\mathrm{mg} / \mathrm{kg})\end{array}$ & $\begin{array}{c}\text { Blood level } \\
(\mu \mathrm{g} / \mathrm{ml})\end{array}$ & $\begin{array}{c}\text { Therapeutic range } \\
(\mu \mathrm{g} / \mathrm{ml})\end{array}$ & \multicolumn{1}{c}{ References } \\
\hline VPA & 8 & 200 & $174.7 \pm 22.8$ & $40-120$ & Schmidt, 2009 \\
CBZ & 7 & 200 & $13.2 \pm 1.7$ & $4-12$ & Eadie, 2001 \\
PB-Na & 7 & 50 & $40.3 \pm 0.8$ & $12-30$ & Schmidt, 2009 \\
GBP & 7 & 100 & $33.5 \pm 1.4$ & $2-20$ & McLean, 1999 \\
AZA-Na & 12 & 55 & $49.8 \pm 4.0$ & $10-20$ & Granero et al., 2007 \\
DZP & 7 & 5 & $0.15 \pm 0.04$ & $0.2-0.6$ & Ogutu et al., 2002 \\
TPM & 8 & 80 & n.d. & - & - \\
KBr & 7 & 1800 & $1769.1 \pm 204.7$ & $500-1500$ & Ryan and Baumann, 1999 \\
\hline
\end{tabular}

Data are mean \pm SEM. 
Figure 1
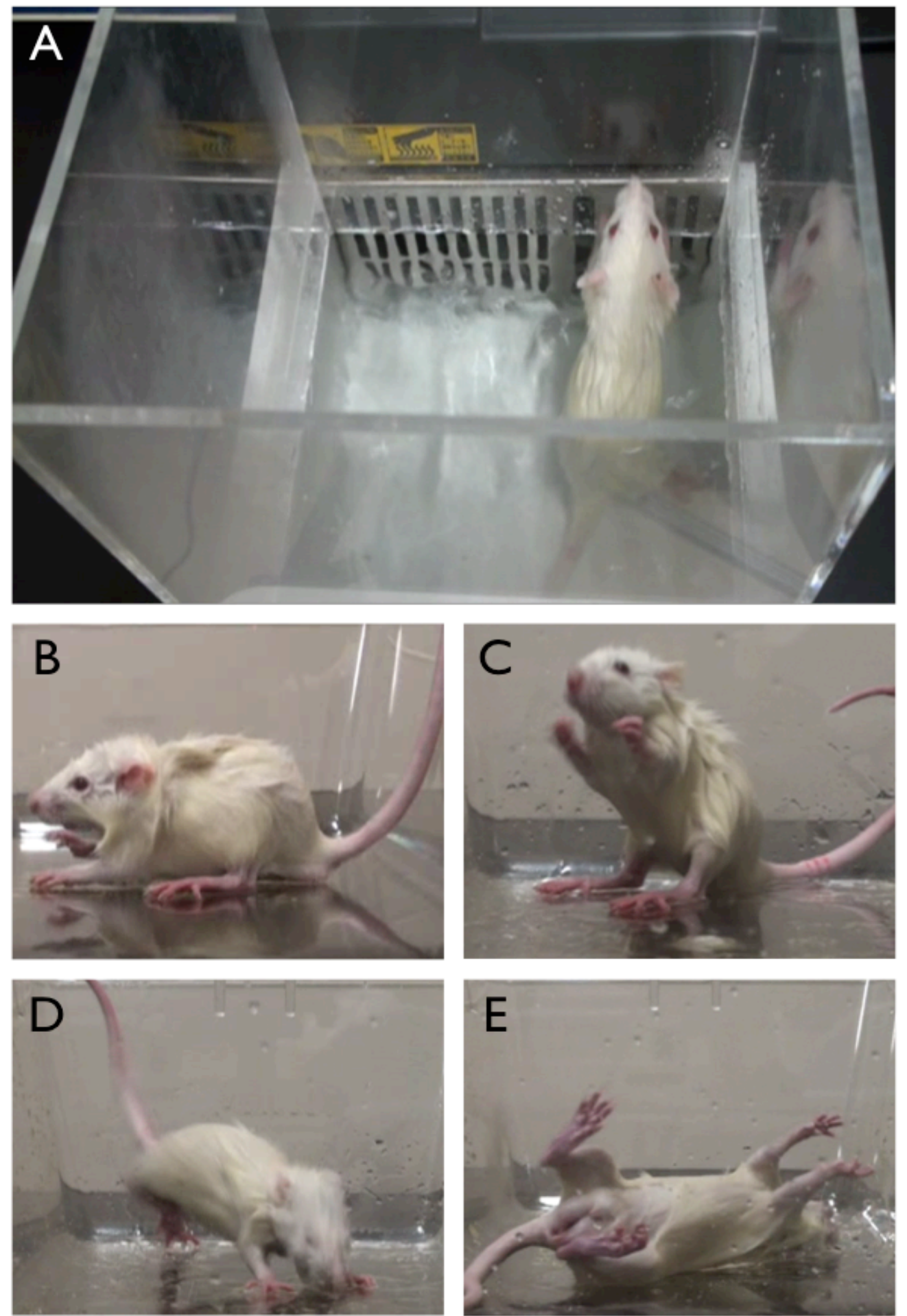
Figure 2

A

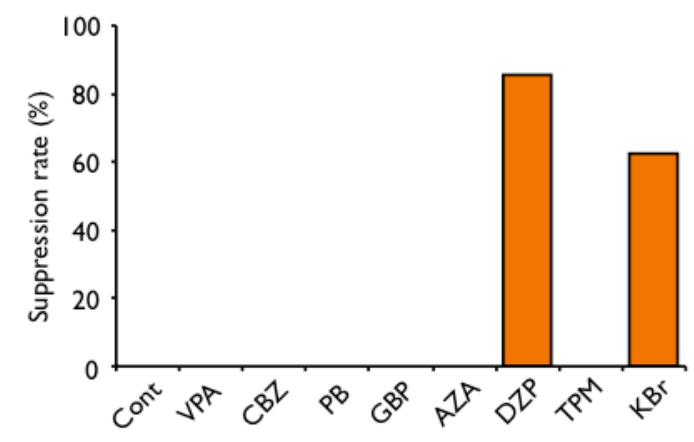

C

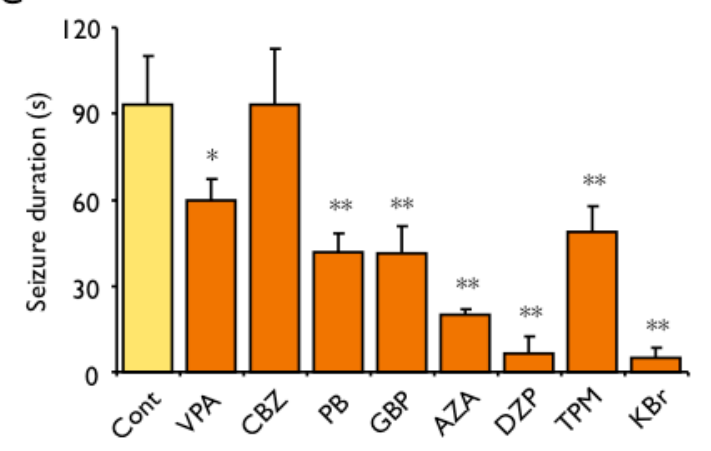

B

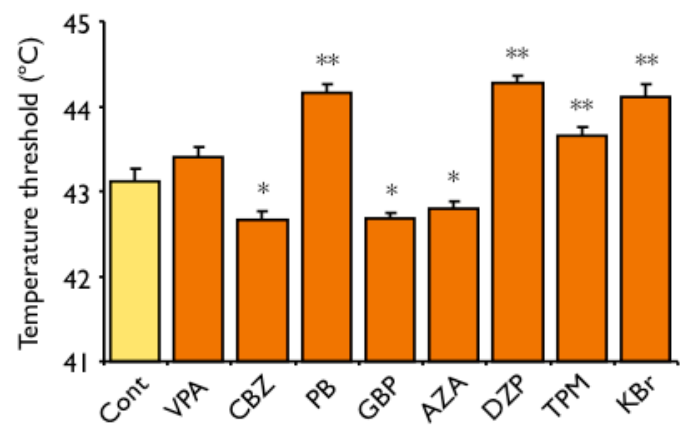

D

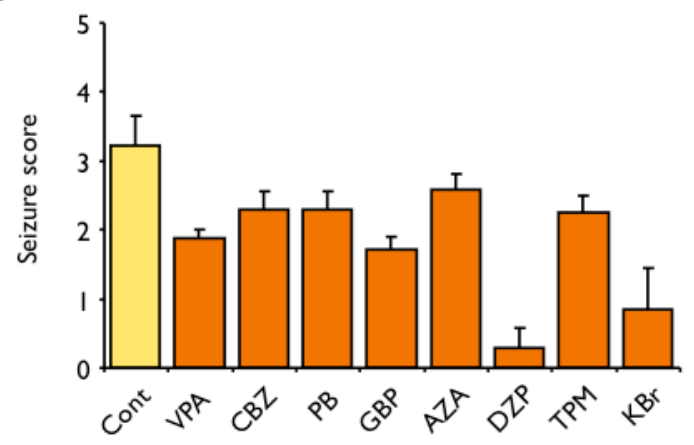




\section{Figure 3}

\section{Untreated}

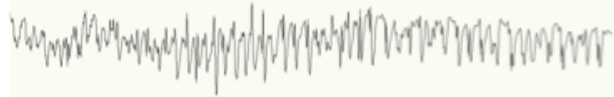

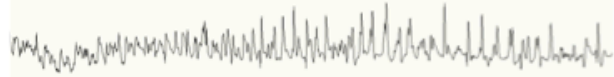

AZA-Na $(55 \mathrm{mg} / \mathrm{kg})$

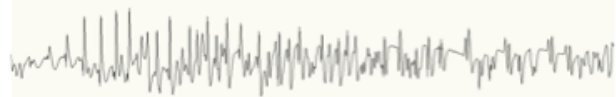

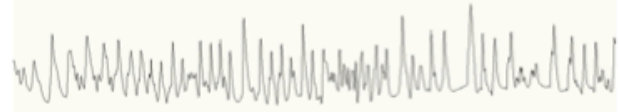

DZP $(5 \mathrm{mg} / \mathrm{kg})$

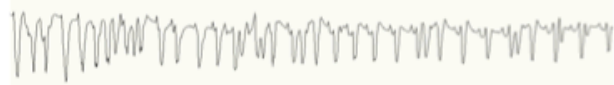

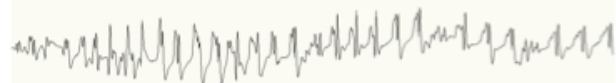

CBZ $(200 \mathrm{mg} / \mathrm{kg})$

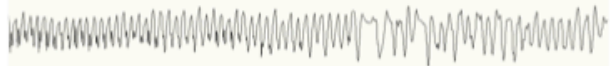

$$
\mathrm{I} \mathrm{mV} \frac{\mathrm{Is}}{\mathrm{I}}
$$

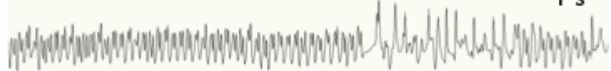

\section{TPM $(80 \mathrm{mg} / \mathrm{kg})$}

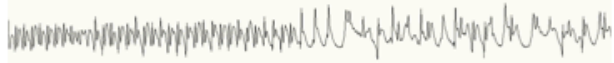

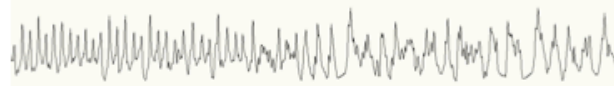

$\mathrm{KBr}(1800 \mathrm{mg} / \mathrm{kg})$

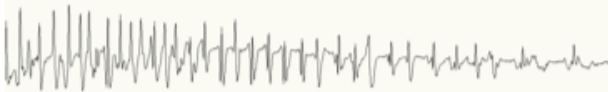

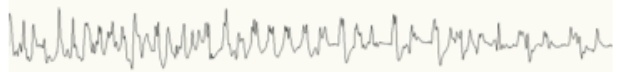


Figure 4

A

Frontal cortex

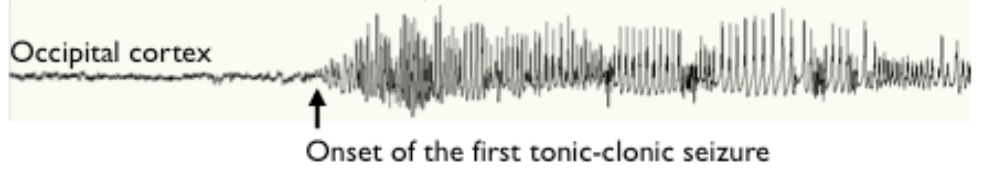

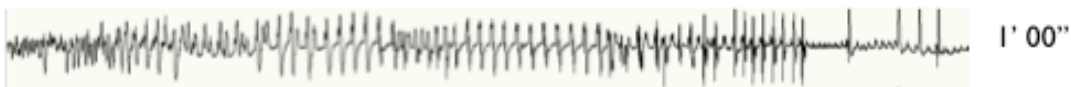

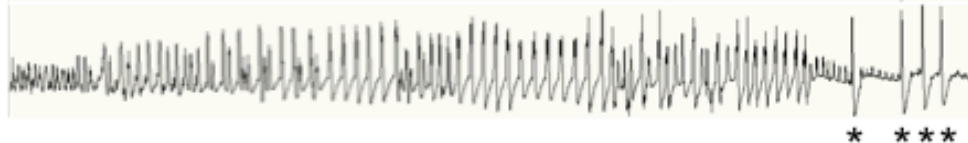

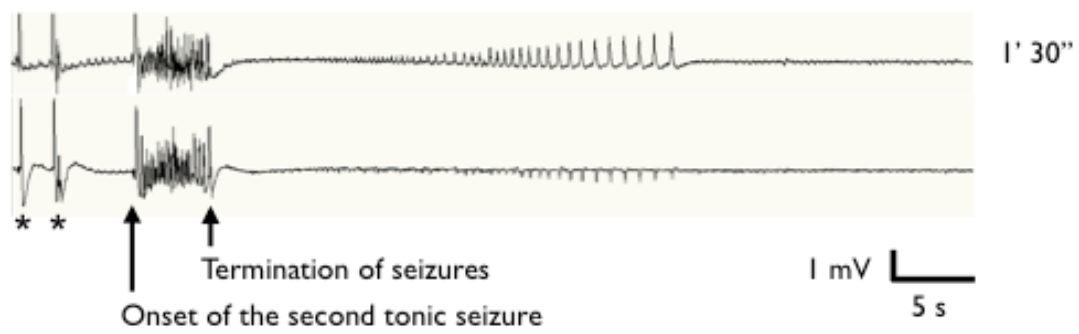

B

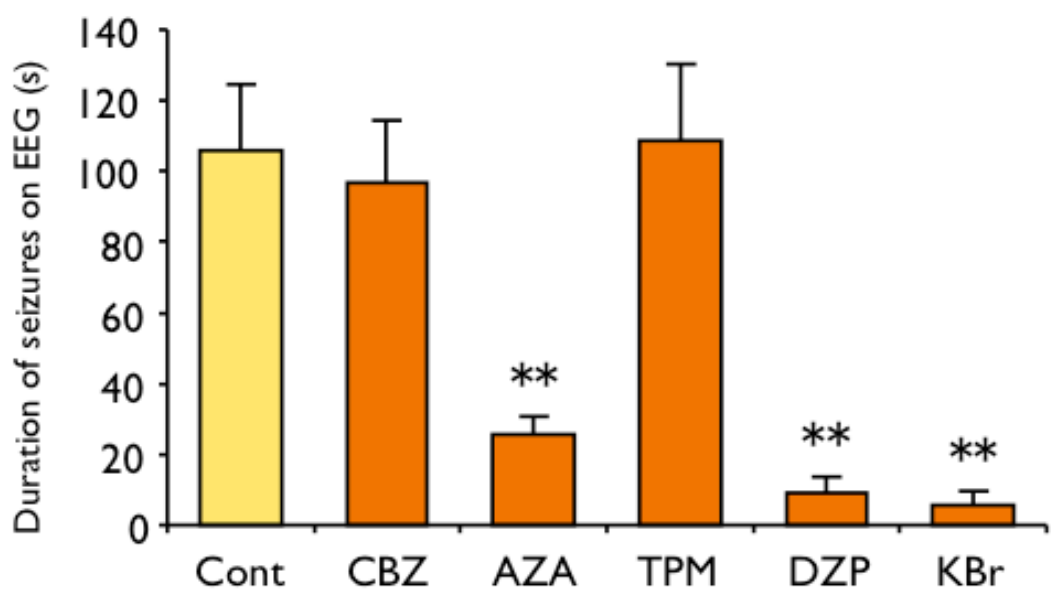


Figure 5
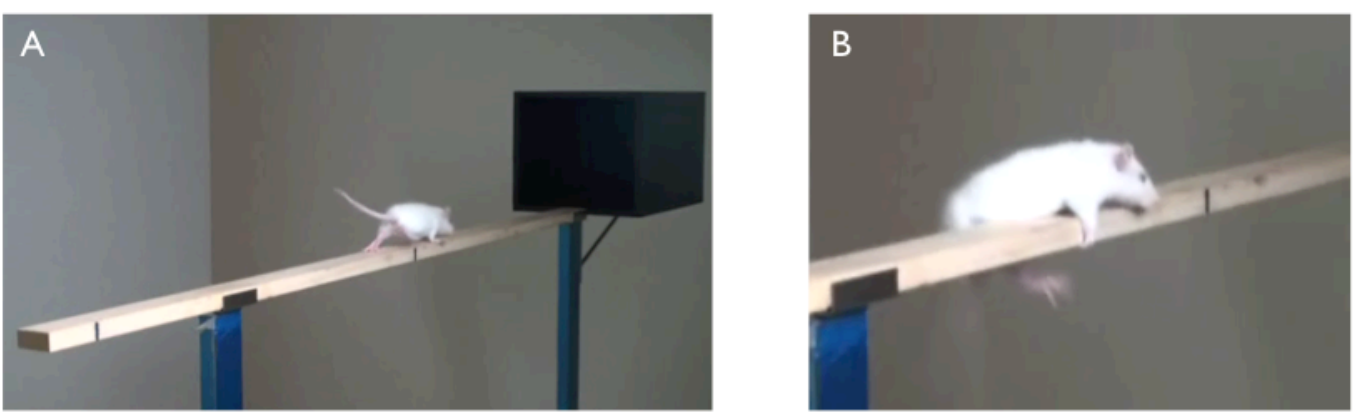

C

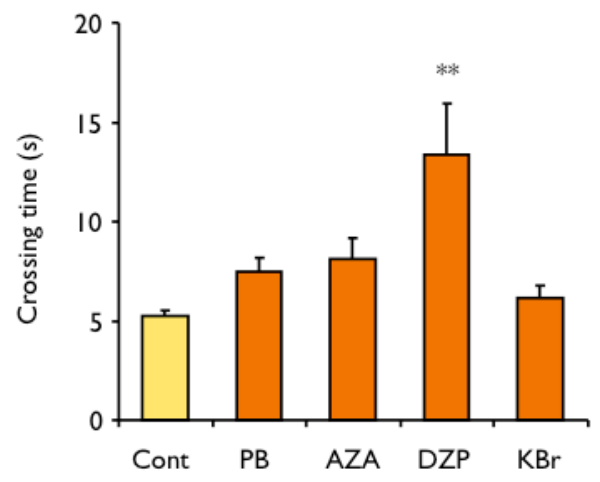

D

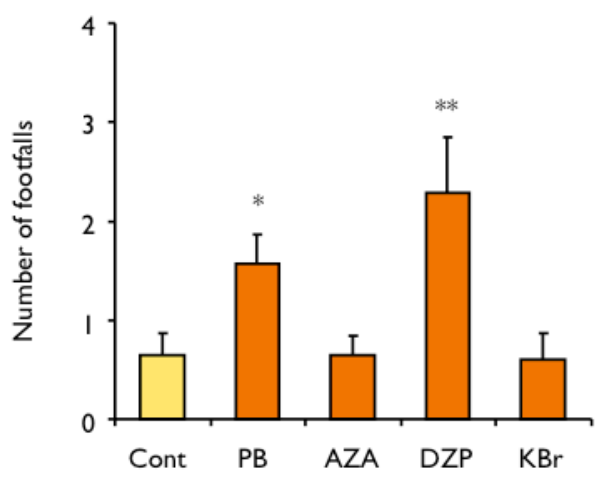

